\title{
Qualidade externa, interna e microbiológica de ovos submetidos a diferentes condições de sanitização, temperatura e períodos de armazenamentos
}

Objetivou-se avaliar o efeito da sanitização, temperatura e período de armazenamento sobre a qualidade física e microbiológica dos ovos de galinha produzidos no município de Itaberaí, Goiás, Brasil. Foram utilizados os delineamentos inteiramente casualizado com dois arranjos fatoriais, sendo: $2 \times 5$, que considerou dois locais de armazenamento e cinco tempos de estocagem, com vinte e quatro ovos por repetição; $2 \times 2$, que considerou duas linhagens de poedeiras e dois procedimentos (lavados e não lavados), com dez repetições. Foram analisadas as qualidades físicas e microbiológicas de um total de 720 ovos de poedeiras das linhagens Hisex White e Hisex Brown. Os dados obtidos foram submetidos à análise de variância, para as variáveis microbiológicas utilizou-se o teste 't' de Student e para as variáveis físicas foi utilizado o teste de Tukey a $5 \%$ de significância, com o auxílio do software estatístico SISVAR $^{\circledR}$. Os resultados da qualidade física dos ovos de ambas as linhagens de poedeiras mostraram que os ovos armazenados em temperatura ambiente apresentaram baixa qualidade interna em comparação com os ovos refrigerados, por um período de 1, 7, 14, 21 e 28 dias de estocagem. A qualidade microbiológica da superfície da casca e conteúdo dos ovos lavados mostrou-se eficaz em comparação ao não lavados. Diante disso, o presente estudo relata a importância da lavagem e refrigeração dos ovos comerciais.

Palavras-chave: Albúmen; Avicultura; Casca; Gema; Microbiologia; Resistência.

\section{External, internal and microbiological quality of eggs submitted to different conditions of sanitization, temperature and storage periods}

\begin{abstract}
The objective was to evaluate the effect of sanitization, temperature and storage period on the physical and microbiological quality of chicken eggs produced in the municipality of Itaberaí, Goiás, Brazil. The completely randomized designs were used with two factorial arrangements, being: $2 \times 5$, which considered two storage locations and five storage times, with twenty-four eggs per repetition; $2 \times 2$, which considered two lines of laying and two procedures (washed and not washed) with ten repetitions. The physical and microbiological qualities of a total of 720 laying eggs of the lines Hisex White and Hisex Brown were analyzed. The data obtained were subjected to analysis of variance, for the microbiological variables the Student's ' $t$ ' test was used and for the physical variables the Tukey test at $5 \%$ significance was used, with the aid of the SISVAR ${ }^{\circledast}$ statistical software. The results of the physical quality of the eggs of both laying lines showed that the eggs stored at room temperature showed low internal quality compared to the refrigerated eggs, for a period of 1, 7, 14, 21 and 28 days of storage. The microbiological quality of the surface of the shell and content of the washed eggs was effective compared to the non-washed ones. Therefore, the present study reports the importance of washing and cooling commercial eggs.
\end{abstract}

Keywords: Albumin; Poultry; Shell; Yolk; Microbiology; Resistance

Topic: Microbiologia Agrícola e Ambiental

Reviewed anonymously in the process of blind peer.
Received: 02/02/2021

Approved: 26/02/2021
Vilson Matias Pinto (D)

Universidade Estadual de Goiás, Brasil

http://lattes.cnpq.br/5695629139120624

http://orcid.org/0000-0003-2243-622X

vimatiashti@hotmail.com

Fernanda Rodrigues Taveira Rocha (id

Universidade Estadual de Goiás, Brasil

http://lattes.cnpq.br/6975292352977483

http://orcid.org/0000-0002-4671-2017

fernanda.rocha@ueg.br

Karyne Oliveira Coelho (iD

Universidade Estadual de Goiás, Brasil

http://lattes.cnpq.br/4493179418459800

http://orcid.org/0000-0002-0844-1324

karyne.coelho@ueg.br

DOI: $10.6008 / C B P C 2179-6858.2021 .002 .0014$

\author{
Paulo Ricardo de Sá da Costa Leite (10 \\ Instituto Federal Goiano, Brasil \\ http://lattes.cnpq.br/0274221319520789 \\ http://orcid.org/0000-0002-5649-4391 \\ paulo.ricardo@ifgoiano.edu.br \\ José Carlos de Sousa Júnior \\ Universidade Estadual de Goiás, Brasil \\ http://lattes.cnpq.br/9146562480275155 \\ http://orcid.org/0000-0003-2578-8140 \\ josecarlos.junior@ifgoiano.edu.br
}

Referencing this:

PINTO, V. M.; ROCHA, F. R. T.; COELHO, K. O.; LEITE, P. R. S. C.; SOUSA JÚNIOR, J. C.. Qualidade externa, interna e microbiológica de ovos submetidos a diferentes condições de sanitização, temperatura e períodos de armazenamentos. Revista Ibero Americana de Ciências Ambientais, v.12, n.2, p.135-147, 2021. DOI:

http://doi.org/10.6008/CBPC2179-6858.2021.002.0014 


\section{INTRODUÇÃO}

O ovo é considerado um dos alimentos mais completos da dieta humana, sendo uma fonte de proteína de alto valor biológico contendo: minerais, vitaminas, ácidos graxos, entre outros elementos benéficos à saúde e prevenção contra doenças, além de ser um alimento barato o que permite o consumo pela população de menor renda (PASCOAL et al., 2008; RIBEIRO et al., 2015). No entanto é perecível e deve ser conservado adequadamente, durante todo o período de comercialização e armazenamento, tendo em vista que sua perda de qualidade é inevitável e pode ser agravada devido aos fatores como umidade relativa, temperatura e estado nutricional das poedeiras (ARRUDA et al., 2019).

O tempo de armazenamento diminui a qualidade interna dos ovos, podendo ser mais agravante, quando são mantidos em ambientes sem controle de temperatura e umidade. Pesquisas afirmam que a qualidade de ovos de poedeiras armazenados em diferentes temperaturas e períodos de estocagem foi alterada, quando mantidos em ambiente com maior temperatura (20 a $24^{\circ} \mathrm{C}$ ) e menor umidade $(60 \%)$, os quais potencializaram essa diminuição da qualidade à medida que se avançava o período do armazenamento (GARCIA et al., 2010; HONORATO et al., 2016).

A legislação brasileira não estabelece a obrigatoriedade do procedimento de refrigeração para estabelecimentos comerciais, quanto ao armazenamento de ovos, fato este que afeta a qualidade desse alimento na cadeia produtiva (LANA et al., 2017). A perda da qualidade também está relacionada com a contaminação por microrganismos no interior dos ovos, causada tanto pelas condições das instalações, manejo, manipulação e armazenamento dos ovos, quanto pela própria ave, ou seja, podendo ser por meio de transmissão vertical ou horizontal (CALEGARI et al., 2019).

Os microrganismos não contaminam apenas a casca do ovo, mas também podem penetrar o seu interior e provocar deterioração do alimento (BARCELOS et al., 2017). Isto pode ser decorrente da temperatura, procedimento e armazenamento inadequados, aumentando a probabilidade de crescimento microbiano nos ovos, como bactérias e fungos (STRINGHINI et al., 2009; COSTA et al., 2016).

Nesse sentido, estudos sobre qualidade física e microbiológica dos ovos são fundamentais para identificar problemas nestes produtos, o que, às vezes, pode causar risco à saúde dos consumidores. Diante disso, objetivou-se avaliar o efeito da sanitização, temperatura e período de armazenamento sobre a qualidade físico-química e microbiológica dos ovos de poedeiras comerciais.

\section{MATERIAIS E MÉTODOS}

Os ovos foram adquiridos de um criatório de poedeiras das linhagens Hisex White e Hisex Brown com idade entre 65 a 70 semanas, que foram criadas na propriedade Fazenda Sítio Grande, localizada no município de Itaberaí, Goiás, Brasil. Os mesmos foram coletados, armazenados e transportados para o laboratório de alimentos da Fazenda Escola da Universidade Estadual de Goiás - Campus São Luís dos Montes Belos, para realização das análises físicas e microbiológicas. 
Qualidade externa, interna e microbiológica de ovos submetidos a diferentes condições de sanitização, temperatura e períodos de

foram secos em papel toalha associado a ventilação e temperatura de $28^{\circ} \mathrm{C}$ por 10 segundos. Para verificar o nível de ppm de cloro na água foi utilizado fita de medir cloro. A água utilizada para lavagem estava $10^{\circ} \mathrm{C}$ acima da temperatura ambiente e com níveis de cloro inferior a $50 \mathrm{ppm}$, seguindo as normas gerais de inspeção de ovos e derivados, e também, as recomendações para agroindústrias de pequeno porte de ovos de galinha (BRASIL, 1990; BRASIL, 2017).

Após a lavagem e secagem, os ovos foram colocados em novas embalagens e armazenados em duas diferentes condições de temperatura: sala fechada à temperatura ambiente e refrigeração com temperatura de aproximadamente $5^{\circ} \mathrm{C}$, ambas as condições de armazenamento isentas de radiação por luz. As mesmas condições de armazenamento também foram utilizadas para os ovos que não receberam procedimento de lavagem. Dentre os 480 ovos utilizados para avaliar a qualidade física, metade foi submetida ao armazenamento em temperatura ambiente e a outra metade submetida à refrigeração com temperatura controlada.

Durante o período de armazenamento foi realizado o monitoramento diário da temperatura e umidade até o momento das análises laboratoriais, utilizando um termohigrômetro digital e os valores da temperatura de armazenamento e umidade relativa do ar podem ser visualizadas na Tabela 2.

Tabela 2: Valores de temperatura e umidade de 1 a 28 dias de armazenamento dos ovos.

\begin{tabular}{|c|c|c|c|}
\hline Ambiente & & & \\
\hline & Máxima & Mínima & Média \\
\hline Temperatura $\left({ }^{\circ} \mathrm{C}\right)$ & 29,27 & 25,57 & 27,42 \\
\hline Umidade (\%) & 70,84 & 57,79 & 64,31 \\
\hline \multicolumn{4}{|l|}{ Refrigerado } \\
\hline & Máxima & Mínima & Média \\
\hline Temperatura $\left({ }^{\circ} \mathrm{C}\right)$ & 8,65 & 1,84 & 5,24 \\
\hline Umidade (\%) & 63,73 & 23,07 & 43,40 \\
\hline
\end{tabular}

Para determinar as características referentes à qualidade físico-química dos ovos, foram avaliados: peso do ovo; altura do albúmen; coloração da gema; Unidade Haugh; pH de gema e albúmen, espessura e peso da casca; resistência da casca e padrão de qualidade do ovo. Foram utilizados seis ovos para determinar o pH do albúmen e gema, realizando sua separação e homogeneização, em seguida, aferidos com pHmetro digital de bancada.

Após finalizar as análises de $\mathrm{pH}$, separou-se as seis cascas para determinar o peso e espessura da casca, na qual, foram determinados com auxílio de uma balança digital de bancada e um paquímetro digital, respectivamente. Após a lavagem das cascas para remoção do albúmen remanescente, houve um período de secagem em temperatura ambiente por um período de 24 a 48 horas, antes destes procedimentos de pesagem e medição da espessura. Para determinar a qualidade física das demais análises, utilizaram-se doze ovos por tratamento no equipamento Egg Analyzer ${ }^{\mathrm{TM}} \circledast$, que informa: peso do ovo, altura do albúmen, coloração da gema, padrão de qualidade e Unidade Haugh. Para se determinar a resistência da casca, seis ovos de cada tratamento foram submetidos ao equipamento Egg Tester ${ }^{\circledR}$, cujos resultados expressos em Kgf. 
Qualidade externa, interna e microbiológica de ovos submetidos a diferentes condições de sanitização, temperatura e períodos de

Na realização das análises microbiológicas foi utilizado um pool de seis ovos por repetição em cada tratamento, totalizando 240 ovos. Seis ovos inteiros foram acondicionados em sacos plásticos estéreis e adicionados de $60 \mathrm{ml}$ de solução salina peptonada, tamponada a 1\%, que foram homogeneizados, cuidadosamente durante 10 minutos para que a solução atingisse toda a superfície das cascas dos ovos. Sem seguida esta solução oriunda da lavagem foi colocada em um recipiente estéril para posteriores diluições seriadas e análises, sendo considerada, neste recipiente, a diluição $10^{\circ}$ da casca dos ovos.

Estes mesmos ovos, foram transferidos para outro Stomacher e imersos em $150 \mathrm{ml}$ de álcool etílico a 70\%, por cinco minutos e secos com papel toalha absorvente. Estes ovos foram abertos assepticamente e seu conteúdo colocado em um recipiente estéril, que foi homogeneizado por 60 segundos. Posteriormente foram utilizados $25 \mathrm{ml}$ do conteúdo dos ovos homogeneizados em $225 \mathrm{ml}$ de água peptonada, tamponada a 1\%, sendo considerada, neste recipiente a diluição de $10^{-1}$ do conteúdo dos ovos (VANDERZANT et al., 2010).

Em ambas as amostras foram realizadas diluições seriadas até $10^{-3} \mathrm{em}$ água peptonada $0,1 \%$. A partir das diluições $10^{0}, 10^{-1}$ e $10^{-2}$ da casca e $10^{-1}, 10^{-2}$ e $10^{-3}$ do conteúdo dos ovos foi inoculado $1 \mathrm{ml}$ em petrifilm, para Mesófilos Aeróbios Facultativos Viáveis, Bolores e Leveduras, Staphylococcus aureus, Escherichia coli e Enterobacteriaceae. Durante a contagem foram considerados somente os petrifilm que apresentaram de 25 a 250 colônias, multiplicadas à sua média aritmética pelo respectivo fator de diluição e expressos os resultados em Unidades Formadoras de Colônias/1,0 grama de amostra (UFC/g), seguindo os métodos analíticos de 3M Microbiology Products.

Os dados obtidos da contagem de Mesófilos Aeróbios Facultativos Viáveis, Bolores e Leveduras, Staphylococcus aureus, Escherichia coli e Enterobacteriaceae foram logarizados e submetidos ao teste de ' $\mathrm{t}$ ' de Student $(\mathrm{P} \leq 0,05)$. Os dados das análises físicas foram submetidos à análise de variância e as diferenças das médias comparadas pelo teste de Tukey a 5\% de significância, com o auxílio do software estatístico SISVAR $^{\circledR}$.

\section{RESULTADOS E DISCUSSÃO}

$\mathrm{Na}$ Tabela 3 podem ser visualizados os dados de avaliação da qualidade da casca de ovos de poedeiras das linhagens Hisex White e Hisex Brown, submetidos a diferentes períodos e temperaturas de armazenamento, nos quais se pode observar que não houve influências entre os efeitos do tempo e temperatura sobre o peso, espessura e resistência da casca. Esse fato é esperado pois ambas as linhagens de poedeiras tinham a mesma idade e foram criadas em único aviário, recebendo o mesmo manejo operacional e nutricional.

Os dados da qualidade externa corroboram com os estudos realizados por Almeida et al. (2019), que ao avaliarem cinco diferentes linhagens de galinhas, com 65 a 70 semanas de idade, não foi observado efeito significativo sobre a espessura da casca, além disso, foram considerados ovos com pouca chance de sofrer danos físicos pois apresentam valores superiores a 0,33 $\mathrm{mm}$ de espessura de casca. Segundo Vieira Filho et al. (2017) na avaliação da qualidade física de ovos de três diferentes linhagens de poedeiras (Lohmann LSL, 
Hy-Line W-36 e Lohmann Brown), observaram que não houve diferença significativa na resistência e espessura de casca, apresentando valores médios de $3,88 \mathrm{~g} \mathrm{~cm}^{2}$ e $0,36 \mathrm{~mm}$, respectivamente. Vilela et al. (2016) afirmam que a espessura diminui devido ao tamanho do ovo aumentar mais rapidamente com a idade da poedeira do que o peso da casca. Portanto, com o envelhecimento das poedeiras ocorre uma menor absorção intestinal de cálcio e aumenta o tamanho dos ovos, podendo assim, interferir no peso, espessura e resistência da casca (FIGUEIREDO et al., 2011).

Tabela 3: Valores médios de Peso da Casca (PC), Espessura de Casca (EC) e Resistência da Casca (RC) de ovos de poedeiras das linhagens Hisex White e Hisex Brown de acordo com o período de estocagem e condição de armazenamento.

\begin{tabular}{|c|c|c|c|c|}
\hline \multirow{2}{*}{ Período de Estocagem } & \multicolumn{2}{|c|}{ Hisex White } & \multicolumn{2}{|c|}{ Hisex Brown } \\
\hline & Ambiente & Refrigerado & Ambiente & Refrigerado \\
\hline & \multicolumn{2}{|c|}{ Peso da Casca (g) } & & \\
\hline 1 dia & $6,36 \mathrm{Aa}$ & $6,57 \mathrm{Aa}$ & $6,26 \mathrm{Aa}$ & $6,76 \mathrm{Aa}$ \\
\hline 7 dias & $6,22 \mathrm{Aa}$ & $6,40 \mathrm{Aa}$ & $6,77 \mathrm{Aa}$ & $6,62 \mathrm{Aa}$ \\
\hline 14 dias & $6,05 \mathrm{Aa}$ & 6,29 Аа & $6,44 \mathrm{Aa}$ & 6,99 Аа \\
\hline 21 dias & $6,36 \mathrm{Aa}$ & $6,44 \mathrm{Aa}$ & $6,60 \mathrm{Aa}$ & $7,27 \mathrm{Aa}$ \\
\hline 28 dias & 6,07 Aa & 6,85 Aa & $6,56 \mathrm{Aa}$ & $7,30 \mathrm{Aa}$ \\
\hline CV (\%) & 10,78 & & 10,97 & \\
\hline \multirow[t]{2}{*}{ Valor $\mathrm{P}$} & 0,735 & & 0,459 & \\
\hline & \multicolumn{2}{|c|}{ Espessura da Casca (mm) } & & \\
\hline 1 dia & $0,40 \mathrm{Aa}$ & $0,37 \mathrm{Aa}$ & $0,35 \mathrm{Aa}$ & $0,38 \mathrm{Aa}$ \\
\hline 7 dias & $0,38 \mathrm{Aa}$ & $0,36 \mathrm{Aa}$ & $0,36 \mathrm{Aa}$ & $0,38 \mathrm{Aa}$ \\
\hline 14 dias & 0,37 Аа & 0,36 Аа & 0,38 Аа & $0,37 \mathrm{Aa}$ \\
\hline 21 dias & $0,40 \mathrm{Aa}$ & 0,39 Аа & 0,38 Аа & $0,40 \mathrm{Aa}$ \\
\hline 28 dias & $0,38 \mathrm{Aa}$ & $0,40 \mathrm{Aa}$ & $0,38 \mathrm{Aa}$ & $0,41^{\mathrm{Aa}}$ \\
\hline CV (\%) & 11,03 & & 8,97 & \\
\hline \multirow[t]{2}{*}{ Valor P } & 0,758 & & 0,109 & \\
\hline & \multicolumn{2}{|c|}{ Resistência da Casca (Kgf) } & & \\
\hline 1 dia & $3,54 \mathrm{Aa}$ & $3,35 \mathrm{Aa}$ & $3,30 \mathrm{Aa}$ & $3,21^{\mathrm{Aa}}$ \\
\hline 7 dias & $4,34 \mathrm{Aa}$ & $3,47 \mathrm{Aa}$ & $3,92 \mathrm{Aa}$ & $3,05 \mathrm{Aa}$ \\
\hline 14 dias & $4,00 \mathrm{Aa}$ & $4,21 \mathrm{Aa}$ & $3,44 \mathrm{Aa}$ & $3,30 \mathrm{Aa}$ \\
\hline 21 dias & $4,20 \mathrm{Aa}$ & $4,55 \mathrm{Aa}$ & $3,97 \mathrm{Aa}$ & $4,30 \mathrm{Aa}$ \\
\hline 28 dias & 4,18 Аa & $3,43 \mathrm{Aa}$ & $4,26 \mathrm{Aa}$ & $4,20 \mathrm{Aa}$ \\
\hline CV (\%) & 30,17 & & 28,61 & \\
\hline Valor $\mathrm{P}$ & 0,802 & & 0,730 & \\
\hline
\end{tabular}

Médias seguidas pela mesma letra maiúsculas nas linhas e minúsculas nas colunas não diferem pelo teste de Tukey $(P \leq 0,05) ; C V=$ Coeficiente de Variação.

Na Tabela 4 pode-se observar que independente da temperatura a que foram submetidos, houve redução na coloração da gema dos ovos das poedeiras das linhagens Hisex White e Hisex Brown até o período de 28 dias de estocagem, no entanto, alguns valores de coloração de gema foram superiores nos ovos armazenados no ambiente com relação aqueles mantidos refrigerados.

Para Yadgary et al. (2010) quando os ovos são armazenados durante um maior período, sofrem alteração na sua coloração de gema em função da passagem de proteínas do albúmen para gema, tornandoa com cor salmão. Além deste processo, as moléculas de ferro presentes na gema migram rapidamente para o albúmen, tornando-a com cor rósea, provocando queda na coloração da gema dos ovos (PAIVA et al., 2019). Além disso, a cor da gema pode apresentar grandes variações na pigmentação, variando do amarelo levemente claro ao laranja escuro, de acordo com a níveis nutricionais da alimentação e características individuais das linhagens de poedeiras. 
Qualidade externa, interna e microbiológica de ovos submetidos a diferentes condições de sanitização, temperatura e períodos de armazenamentos

PINTO, V. M.; ROCHA, F. R. T.; COELHO, K. O.; LEITE, P. R. S. C.; SOUSA JÚNIOR, J. C.

Tabela 4: Valores médios de Cor de Gema (CG), pH de Gema (PHG) e pH do Albúmen (PHA) de ovos de poedeiras das linhagens Hisex White e Hisex Brown de acordo com o período de estocagem e condição de armazenamento.

\begin{tabular}{|c|c|c|c|c|}
\hline \multirow{2}{*}{ Período de Estocagem } & \multicolumn{2}{|c|}{ Hisex White } & \multicolumn{2}{|c|}{ Hisex Brown } \\
\hline & Ambiente & Refrigerado & Ambiente & Refrigerado \\
\hline & \multicolumn{4}{|c|}{ Cor da Gema } \\
\hline 1 dia & 11,08 Аа & $10,70 \mathrm{Aa}$ & $11,50 \mathrm{Aa}$ & $10,80 \mathrm{Ba}$ \\
\hline 7 dias & $11,04 \mathrm{Aa}$ & 9,90 Bab & 11,10 Aab & $10,42 \mathrm{Bab}$ \\
\hline 14 dias & $10,80 \mathrm{Aab}$ & $9,20^{\mathrm{Bb}}$ & $10,50^{\mathrm{Ab}}$ & 10,43 Aab \\
\hline 21 dias & $9,40 \mathrm{Ac}$ & $9,27^{A b}$ & $9,40^{A c}$ & $10,00 \mathrm{Ab}$ \\
\hline 28 dias & $9,80 \mathrm{Abc}$ & $9,10^{\mathrm{Bb}}$ & $9,50 \mathrm{Ac}$ & $9,70 \mathrm{Ab}$ \\
\hline CV (\%) & 9,08 & & 5,94 & \\
\hline \multirow[t]{2}{*}{ Valor P } & 0,010 & & 0,004 & \\
\hline & \multicolumn{4}{|c|}{$\mathrm{pH}$ da Gema } \\
\hline 1 dia & $6,49 \mathrm{Ab}$ & $6,53^{A b}$ & $6,38 \mathrm{Ac}$ & $6,51 \mathrm{Aa}$ \\
\hline 7 dias & $6,46^{\mathrm{Bb}}$ & $6,64 \mathrm{Ab}$ & $6,55^{A c}$ & $6,60 \mathrm{Aa}$ \\
\hline 14 dias & $6,74 \mathrm{Aa}$ & 6,71 Aab & $6,63 \mathrm{Abc}$ & $6,50 \mathrm{Aa}$ \\
\hline 21 dias & $6,85 \mathrm{Aa}$ & $6,76 \mathrm{Aab}$ & 6,89 Aab & $6,58 \mathrm{Ba}$ \\
\hline 28 dias & $6,90 \mathrm{Aa}$ & 6,89 Аa & 6,93 Аa & $6,65^{\mathrm{Ba}}$ \\
\hline CV (\%) & 2,22 & & 2,39 & \\
\hline \multirow[t]{2}{*}{ Valor P } & 0,234 & & 0,003 & \\
\hline & \multicolumn{4}{|c|}{ pH do Albúmen } \\
\hline 1 dia & $8,89 \mathrm{Ab}$ & $8,47^{\mathrm{Bc}}$ & $8,60^{A c}$ & $8,68^{A b}$ \\
\hline 7 dias & 9,46 Аа & $9,12 \mathrm{Bb}$ & $9,11 \mathrm{Ab}$ & 9,02 Аа \\
\hline 14 dias & 9,58 Аа & $9,21 \mathrm{Bab}$ & 9,51 Аа & $9,06 \mathrm{Ba}$ \\
\hline 21 dias & $9,55^{\mathrm{Aa}}$ & $9,22 \mathrm{Bab}$ & $9,52 \mathrm{Aa}$ & $9,11^{\mathrm{Ba}}$ \\
\hline 28 dias & $9,51^{\mathrm{Aa}}$ & $9,32 \mathrm{Ba}$ & 9,56 Aa & $9,21^{\mathrm{Ba}}$ \\
\hline CV (\%) & 1,23 & & 2,19 & \\
\hline Valor P & 0,158 & & 0,008 & \\
\hline
\end{tabular}

Médias seguidas pela mesma letra maiúsculas nas linhas e minúsculas nas colunas não diferem pelo teste de Tukey $(P \leq 0,05) ; C V=$ Coeficiente de Variação.

Verificou-se também que o período de armazenamento influenciou o pH da gema e do albúmen que se comportou de maneira crescente com relação aos períodos de estocagem, estando em condições de temperatura ambiente ou de refrigeração. As condições de armazenamento influenciaram o pH do albúmen dos ovos, que foi inferior quando mantidos em condições de refrigeração (Tabela 4).

Esse dado relacionado ao pH corrobora com Pissinati et al. (2014) e Saccomani et al. (2019) que afirmaram que estas alterações no pH ocorrem devido à perda de dióxido de carbono através dos poros da casca, de modo a alterar o sabor do ovo e piorar sua qualidade interna. E corrobora com Viana et al. (2017) que relataram que ovos refrigerados apresentam valores menores de $\mathrm{pH}$ da gema e do albúmen, quando comparados com os ovos mantidos em temperatura ambiente, independente do período de estocagem. Neste estudo, o pH do albúmen variou entre 9,06 a 9,46 e 8,99 a 9,20 em ovos mantidos em temperatura ambiente e refrigerado, respectivamente, enquanto, o pH da gema variou de 6,46 a 6,74 em temperatura ambiente e de 6,22 a 6,41, quando mantidos sob refrigeramento.

As poedeiras utilizadas nesta pesquisa apresentaram idades entre 65 e 70 semanas e os ovos tiveram peso médio de aproximadamente 64 gramas. Sendo assim, estes foram classificados como tipo "Extra" e/ou "Jumbo", pesando entre 60 a 65 gramas e acima de 66 gramas, respectivamente (BRASIL, 1990). Os ovos tendem a aumentar e variar de peso com o avanço da idade das poedeiras comerciais (CARVALHO et al., 2017).

Diante da Tabela 5, pode-se verificar que apenas os ovos das poedeiras da linhagem Hisex White armazenados em temperatura ambiente apresentam efeitos significativos no peso do ovo, durante os cinco 
períodos de estocagem. No entanto, ao comparar as médias do peso dos ovos, entre os dois ambientes, é possível verificar que houve perda maior nos ovos mantidos em temperatura ambiente. Isso ocorre devido à perda de umidade maior do albúmen através dos poros da casca quando são armazenados em temperatura elevadas.

Tabela 5: Valores médios de Peso do Ovo (PO), Altura do Albúmen (AA), Unidade Haugh (HU) e Padrão de Qualidade (PQ) de ovos de poedeiras das linhagens Hisex White e Hisex Brown de acordo com o período de estocagem e condição de armazenamento.

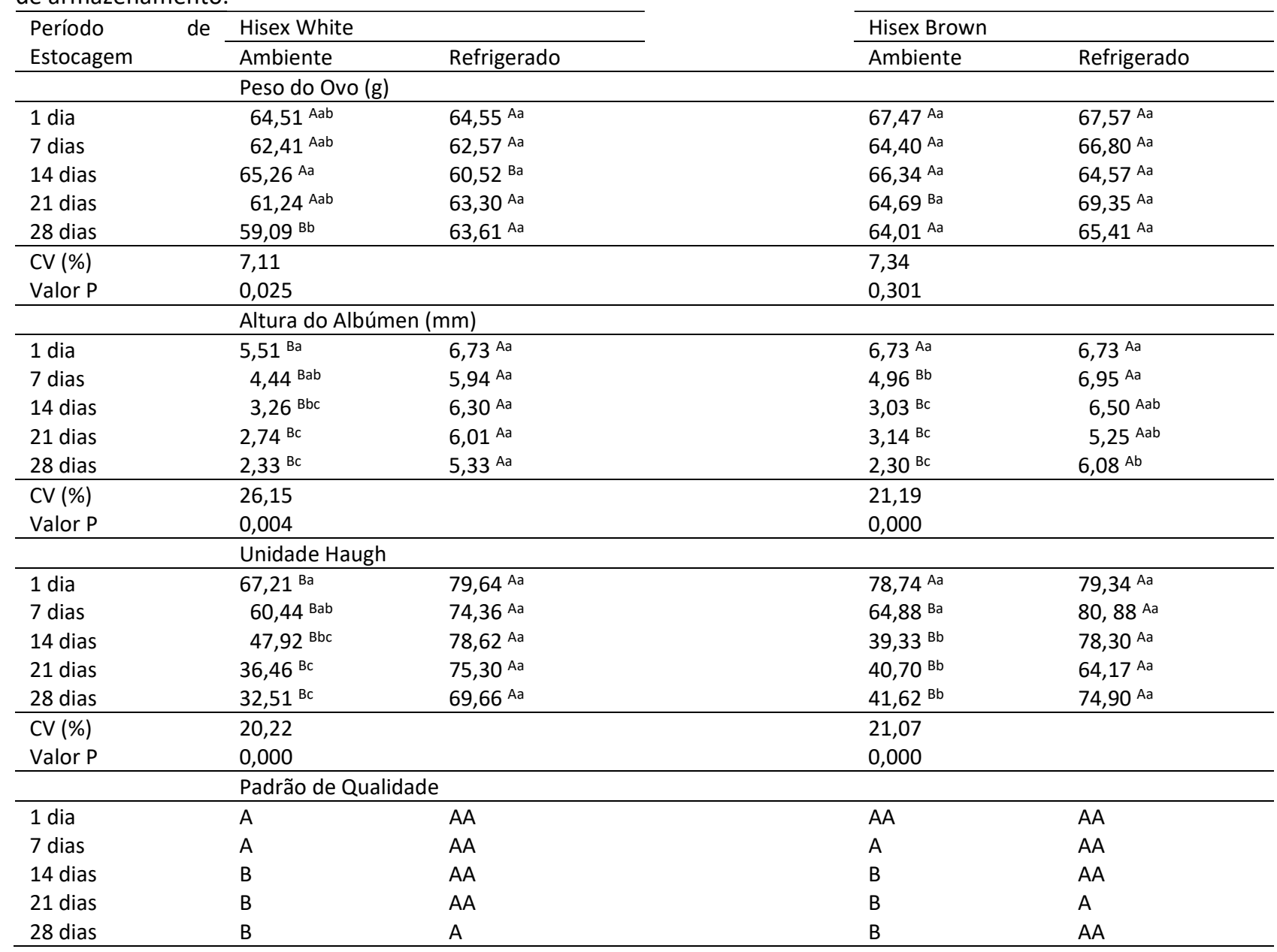

Médias seguidas pela mesma letra maiúsculas nas linhas e minúsculas nas colunas não diferem pelo teste de Tukey $(P \leq 0,05) ; C V=$ Coeficiente de Variação.

Este resultado confirma os estudos de Gherardi et al. (2019) e Garcia et al. (2010) que quando avaliaram a qualidade de ovos de poedeiras da linhagem Hisex Brown, com idades entre 30 a 60 semanas, observaram uma perda de peso mais rápida nos ovos armazenados em temperatura ambiente em comparação com os mantidos sob refrigeração. De acordo com Arruda et al. (2019) ao avaliarem os pesos dos ovos de poedeira da linhagem Hy-Line com idade de 32 semanas, armazenados durante 7, 14, 21 e 28 dias em temperatura ambiente, observaram perda de 4 gramas quando são mantidos até os 28 dias.

Os valores observados da altura do albúmen foram superiores nos ovos das poedeiras das linhagens Hisex White e Hisex Brown que foram submetidos à refrigeração em comparação com aqueles mantidos em temperatura ambiente. Pode-se notar também, que os ovos perdem altura do albúmen rapidamente quando são estocados em ambiente sem refrigeramento, com temperatura de $27,42^{\circ} \mathrm{C}$ e umidade de $64,31 \%$. Como 
Qualidade externa, interna e microbiológica de ovos submetidos a diferentes condições de sanitização, temperatura e períodos de

esperado, a Unidade Haugh dos ovos armazenados no ambiente em diferentes períodos de estocagem apresentou valores inferiores quando comparados aos refrigerados, podendo observar uma perda no padrão de qualidade dos ovos (Tabela 5).

Henriques et al. (2018) relataram que ao avaliarem a qualidade dos ovos vermelhos comerciais mantidos em temperatura ambiente $\left(22^{\circ} \mathrm{C}\right)$ e sob refrigeração $\left(6^{\circ} \mathrm{C}\right)$, observaram que a altura do albúmen diminuiu com o passar do tempo, sendo que, apresentaram menores valores após 14 dias de armazenamento em temperatura ambiente. Segundo Honorato et al. (2016) a diminuição na altura do albúmen é mais acentuada nos ovos mantidos em ambiente sem refrigeração. Portanto, a perda da qualidade do albúmen é provocada pelas enzimas que hidrolisam as cadeias de aminoácidos, que destroem as estruturas proteicas e liberam água ligada as grandes moléculas de proteínas (SILVERSIDES et al., 2004; LEANDRO et al., 2005).

Barbosa et al. (2008) verificaram que os valores médios de Unidade Haugh (UH) dos ovos de quatro diferentes linhagens de poedeiras (Hy-Line branca, Hisex branca, Hy-Line marrom e Hisex marrom) apresentaram declínio até aos 35 dias de estocagem, para ambos locais de armazenamento. Além disso, os piores valores de Unidade Haugh foram atribuídos aos ovos estocados sem controle de temperatura $\left(26,78^{\circ} \mathrm{C}\right)$ e umidade $(39,09 \%)$ em comparação com os mantidos sob controle de temperatura $\left(20,73^{\circ} \mathrm{C}\right)$ e umidade (78,75\%). De acordo com Paiva et al. (2019) a partir do $5^{\circ}$ dia de armazenamento dos ovos das poedeiras leves, com 40 semanas de idade, observou que quando mantidos em temperatura refrigerada apresentaram maiores valores de Unidade Haugh em comparação com aqueles mantidos na temperatura ambiente, por um período de 30 dias.

O padrão de qualidade dos ovos armazenados em temperatura ambiente com $27,42^{\circ} \mathrm{C}$ e umidade de $64,31 \%$, foi considerado inferior a partir do $14^{\circ}$ dia de estocagem, para as linhagens Hisex White e Hisex Brown (Tabela 5). Os ovos apresentam um padrão de qualidade, diante dos valores de Unidade Haugh, sendo assim, o ovo é considerado de qualidade excelente (AA) quando os valores forem superiores a 72 , qualidade alta (A) com valores entre 60 a 71, qualidade inferior (B) com valores entre 31 a 59 e qualidade ruim (C) quando apresentarem valores inferiores a 30.

Quando avaliadas a contagem de Mesófilos Aeróbios Facultativos Viáveis, Bolores e Leveduras, Staphylococcus aureus, Escherichia coli e Enterobacteriaceae, apresentadas na Tabela 6, pode-se notar que não houve influências entre os efeitos do procedimento de sanitização e linhagem de poedeiras comerciais sobre o conteúdo dos ovos. Além disso, também não foram observados efeitos significativos sobre Escherichia coli na superfície de casca dos ovos brancos (Hisex White) e vermelhos (Hisex Brown).

Nos estudos de Jones et al. (2004) também foram observadas baixas concentrações de Enterobacteriaceae na superfície de casca de ovos, sendo que apenas 28 dos 485 ovos não lavados e lavados apresentaram resultados positivos, quando armazenados durante 45 dias, todos os valores foram inferiores a 1,00 log UFC/g, ou seja, não houve diferenças entre os ovos não lavados e lavados em nenhum dos períodos de amostragem, entretanto, a quantidade mais elevada registada foi de 1,40 log UFC/g para um único ovo não lavado. 
Na contagem de Bolores e Leveduras e Staphylococcus aureus na superfície da casca dos ovos das poedeiras da linhagem Hisex White e Hisex Brown, verifica-se maior quantidade de unidades formadoras de colônias nos ovos não lavados em comparação aos lavados, ou seja, quando sanitizados, houve diminuição da contaminação por microrganismos presentes nas superfícies dos ovos brancos e vermelhos. No entanto, a presença de Bolores e Leveduras na casca foi maior nos ovos da linhagem Hisex Brown em ralação aos ovos da linhagem Hisex White (Tabela 6).

Tabela 6: Valores médios das populações microbianas em casca e conteúdo de ovos de acordo com o procedimento de higienização e linhagem de poedeiras comerciais.

\begin{tabular}{|c|c|c|c|c|}
\hline \multirow{2}{*}{ Procedimentos } & \multicolumn{2}{|l|}{ Casca } & \multicolumn{2}{|l|}{ Conteúdo } \\
\hline & Hisex White & Hisex Brown & Hisex White & Hisex Brown \\
\hline & \multicolumn{4}{|c|}{ Mesofilos Aeróbios Facultativos Viáveis (Log UFC/g) } \\
\hline Lavados & $1,91 \mathrm{Aa}$ & $2,41 \mathrm{Ab}$ & $1,18^{\mathrm{Aa}}$ & $1,40 \mathrm{Aa}$ \\
\hline Não lavados & 3,12 Аа & 4,27 Аa & $1,32 \mathrm{Aa}$ & $1,22 \mathrm{Aa}$ \\
\hline CV (\%) & 49,74 & & 49,46 & \\
\hline \multirow[t]{2}{*}{ Valor $\mathrm{P}$} & 0,486 & & 0,430 & \\
\hline & \multicolumn{4}{|c|}{ Staphylococcus aureus (Log UFC/g) } \\
\hline Lavados & $1,19 \mathrm{Ab}$ & $1,95^{\mathrm{Ab}}$ & $1,33 \mathrm{Aa}$ & $1,62 \mathrm{Aa}$ \\
\hline Não lavados & 3,22 Аа & 3,91 Аа & $1,52 \mathrm{Aa}$ & 1,39 Аа \\
\hline CV (\%) & 43,18 & & 49,72 & \\
\hline \multirow[t]{2}{*}{ Valor $\mathrm{P}$} & 0,917 & & 0,372 & \\
\hline & \multicolumn{4}{|c|}{ Escherichia coli (Log UFC/g) } \\
\hline Lavados & $1,00^{\mathrm{Ba}}$ & 1,59 Aa & $1,00 \mathrm{Aa}$ & $1,00^{\mathrm{Aa}}$ \\
\hline Não lavados & $1,00 \mathrm{Aa}$ & $1,00 \mathrm{Ab}$ & 1,16 Аa & $1,00 \mathrm{Aa}$ \\
\hline CV (\%) & 54,93 & & 18,51 & \\
\hline \multirow[t]{2}{*}{ Valor $\mathrm{P}$} & 0,144 & & 0,183 & \\
\hline & \multicolumn{4}{|c|}{ Enterobacteriaceae (Log UFC/g) } \\
\hline Lavados & $1,00 \mathrm{Aa}$ & $1,17 \mathrm{Aa}$ & $1,00 \mathrm{Aa}$ & $1,13 \mathrm{Aa}$ \\
\hline Não lavados & $1,00 \mathrm{Aa}$ & $1,00 \mathrm{Aa}$ & 1,16 Аa & 1,07 Аa \\
\hline CV (\%) & 26,13 & & 31,84 & \\
\hline \multirow[t]{2}{*}{ Valor $\mathrm{P}$} & 0,324 & & 0,318 & \\
\hline & \multicolumn{4}{|c|}{ Bolores e Leveduras (Log UFC/g) } \\
\hline Lavados & $1,00^{\mathrm{Bb}}$ & $1,43 \mathrm{Ab}$ & $1,00^{\mathrm{Aa}}$ & $1,00^{\mathrm{Aa}}$ \\
\hline Não lavados & 1,59 Аа & $2,33 \mathrm{Aa}$ & $1,00 \mathrm{Aa}$ & $1,00 \mathrm{Aa}$ \\
\hline CV (\%) & 34,88 & & 00,00 & \\
\hline Valor $\mathrm{P}$ & 0,376 & & 0,000 & \\
\hline
\end{tabular}

Médias seguidas pela mesma letra maiúsculas nas linhas e minúsculas nas colunas não diferem pelo teste de t-Student $(P \leq 0,05) ; C V=$ Coeficiente de Variação.

Stringhini et al. (2009) afirmaram que os valores de Staphylococcus aureus presentes nas casas dos ovos são reduzidos quando adotados os procedimentos de lavagem, ou seja, ao analisarem os ovos da sala de classificação de duas granjas com sistema de lavagem e duas granjas sem procedimento de lavagem, observaram que valores médios foram de aproximadamente 1,36 log UFC/g e 3,49 log UFC/g, respectivamente. Em se tratando da contagem de bolores e leveduras, Lima et al. (2018) observaram valores $<1,0 \log$ UFC/g até 7,20 log UFC/g, com média de 3,31 log UFC/g. No entanto, nas normas gerais de inspeção de ovos e derivado, os ovos que apresentam fungos tanto na parte interna como externa são considerados impróprios para o consumo humano (BRASIL, 1990).

Pode-se observar que os ovos não lavados das poedeiras da linhagem Hisex Brown apresentou uma contagem superior de Mesófilos Aeróbios Facultativos na superfície da casca. Por outro lado, nesta mesma linhagem, nota-se que a superfície da casca dos ovos apresentou maior número de unidades formadoras de 
Qualidade externa, interna e microbiológica de ovos submetidos a diferentes condições de sanitização, temperatura e períodos de

colônias de Escherichia coli em ovos lavados, quando comparados aos não lavados. No entanto, está contaminação por Escherichia coli não for superior nos ovos vermelhos (Tabela 6).

Costa et al. (2016) quando avaliaram os ovos comercializados nos estabelecimentos, observou que aproximadamente $55 \%$ e $60 \%$ dos ovos que eram lavados e não lavados, respectivamente, em água corrente antes de serem quebrados, apresentaram a presença de Escherichia coli no seu conteúdo. Lima et al. (2018) afirmam que ao avaliar a qualidade microbiana de ovos comercializados em mercados, observou que os valores da contagem de Escherichia coli foram de $<1,0 \log$ UFC/g até 3,70 log UFC/g, com média de 1,32 log UFC/g, em mesófilos aeróbios facultativos viáveis variou de 1,48 log UFC/g até 7,12 log UFC/g, com média de $3,40 \log \mathrm{UFC} / \mathrm{g}$.

Segundo Santos Neto et al. (2019) ovos de poedeiras da linhagem Hisex Brown, com idades entre 35 e 50 semanas, que não foram lavados e nem sanitizados apresentaram 2,40 log UFC/g de mesófilos aeróbios facultativos viáveis na superfície da casca. Enquanto Stringhini et al. (2009) encontrou valores de 3,10 a 4,70 log UFC/g em duas granjas que não adotam os procedimentos de lavagem na sala de classificação de ovos.

Conforme a Resolução RDC $n^{\circ}$ 12, de 2 de janeiro de 2001, que tem por objetivo estabelecer os padrões microbiológicos sanitários para alimentos destinados ao consumo humano, para ovo íntegro cru, preconiza-se ausência de Salmonella spp. em 25 g de amostra (BRASIL, 2001). Além disso, não estabelece valores aceitáveis de bactérias nas cascas dos ovos, mais deixa recomendado que quanto menor for a carga de microrganismos encontrada na casca, menor será o risco de contaminação do conteúdo interno (BRASIL, 1990).

Sabendo da importância da qualidade microbiana dos ovos e tendo em vista que alguns resultados obtidos foram considerados baixos, pode-se afirmar que os valores de Mesófilos Aeróbios Facultativos Viáveis, Bolores e Leveduras, Staphylococcus aureus, Escherichia coli e Enterobacteriaceae são considerados indicadores das condições higiênicas, portanto, verifica-se, com os dados deste experimento que o procedimento de lavagem dos ovos deveria ser aplicado em todas as empresas produtoras de ovos, pois durante este procedimento é eliminada grande quantidade de microrganismos presentes na superfície da casca dos ovos que serão comercializados.

\section{CONCLUSÕES}

Os procedimentos de lavagem e refrigeração dos ovos devem ser adotados pelos pequenos e grandes produtores, para garantir a comercialização adequada e a inocuidade e características desejáveis do alimento ao consumidor.

AGRADECIMENTOS: Ao Centro de Ensino e Pesquisa Animal e Vegetal (CEPAV) e à Universidade Estadual de Goiás (UEG) - Campus Oeste - Sede São Luís de Montes Belos pela concessão da bolsa de estudo. 


\section{REFERÊNCIAS}

ALMEIDA, E. C. J.; CARNEIRO, P. L. S.; NUNES, L. A.; PEREIRA, A. H. R.; FARIAS FILHO, R. V.; MALHADO, C. H. M.; BITTENCOURT, T. C. B. S. C.. Características físicas de ovos de galinhas nativas comparadas a linhagem de postura. Archivos de Zootecnia, v.68, n.261, p.82-87, 2019.

ARRUDA, M. D.; GOUVEIA, J. W. F.; LISBOA, A. C. C.; ABREU, A. C. L.; ABREU, A. K. F.. Avaliação da qualidade de ovos armazenados em diferentes temperaturas. Revista Craibeiras de Agroecologia, v.4, n.1, p.7681, 2019.

BARBOSA, N. A. A.; SAKOMURA, N. K.; MENDONÇA, M. D. O.; FREITAS, E. R.; FERNANDES, J. B. K.. Qualidade de ovos comerciais provenientes de poedeiras comerciais armazenados sob diferentes tempos e condições de ambientes. Ars Veterinária, v.24, n.2, p.127-133, 2008.

BRASIL. Ministério da Agricultura, Pecuária e Abastecimento. Instrução Normativa n. 05, de $\mathbf{1 5}$ de fevereiro de 2017. Estabelecimento agroindustrial de pequeno porte de ovos de galinha e ovos de codorna e derivados. Brasília: MAPA, 2017.

BRASIL. Ministério da Agricultura, Pecuária e Abastecimento. Instrução Normativa n. 01, de 21 de fevereiro de 1990. Normas Gerais de Inspeção de Ovos e Derivados. Brasília: MAPA, 1990.

BRASIL. Ministério da Agricultura, Pecuária e Abastecimento. Resolução RDC $\mathbf{n} .12$ de $\mathbf{2}$ de janeiro de 2001. Aprova o regulamento técnico sobre padrões microbiológicos para alimentos. Brasília: MAPA, 2001.

CALEGARI, S. M.; SOBRINHO, J. C.; SILVA, M. R.; CARMO, J. M. C.; COSTA, A. R.; CARDOZO, S. P.. Microbiologia de ovos comerciais e análise comparativa de ovos lavados e não lavados. In: COLÓQUIO ESTADUAL DE PESQUISA MULTIDISCIPLINAR \& CONGRESSO NACIONAL DE PESQUISA MULTIDISCIPLINAR. Anais. 2019.

CARVALHO, L. S. S.; FERNANDES, E. A.. Formação e qualidade da casca de ovos de reprodutoras e poedeiras comerciais. Medicina Veterinária, v.7, n.1, p.35-44, 2013.

COSTA, V. D. R.; PAIVA, A. N.; BERENCHTEIN, B.; LEHMKUHL, Â. M. D. S.; SANTOS, A. N. D. A.; MOLENEDO, R. R. C.. Avaliação microbiológica em ovos comerciais lavados e não lavados. Revista Científica de Avicultura e Suinocultura, v.2, n.1, p.001-010, 2016.

FIGUEIREDO, T. C.; CANÇADO, S. V.; VIEGAS, R. P.; RÊGO, I. O. P.; LARA, L. J. C.; SOUZA, M. R.; BAIAO, N. C.. Qualidade de ovos comerciais submetidos a diferentes condições de armazenamento. Arquivo Brasileiro de Medicina Veterinária e Zootecnia, v.63, p.953-959, 2011.

GARCIA, E. R. D. M.; ORLANDI, C. C. O.; OLIVEIRA, C. A. L.; CRUZ, F. K.; SANTOS, T. M. B.; OTUTUMI, L. K.. Qualidade de ovos de poedeiras semipesadas armazenados em diferentes temperaturas e períodos de estocagem. Revista Brasileira de Saúde e Produção Animal, v.11, n.2, p.505-518, 2010.

GHERARDI, S. R. M.; VIEIRA, R. P.; ALMEIDA, J. C..

Modificações físico-químicas e das propriedades funcionais de ovos marrons em função do tempo e condição de estocagem. Multi-Science Journal, v.2, n.2, p.20-27, 2019.

HENRIQUES, J. J. K. S.; RODRIGUES, R. B.; UCZAY, M.. Qualidade de ovos comerciais submetidos a diferentes condições de armazenamento. Revista Brasileira de Higiene e Sanidade Animal, v.12, n.2, p.179-189, 2018.

HONORATO, C. A.; SEABRA, B. S.; SIQUEIRA, M. S.; MELGAREJO, M. R.; FRAGA, T. L.. Qualidade e características físicas de ovos comerciais. Nucleus Animalium, v.8, n.2, p.29-36, 2016.

JONES, D. R.; MUSGROVE, M. T.; NORTHCUTT, J. K.. Variations in external and internal microbial populations in shell eggs during extended storage. Journal of Food Protection, v.67, n.12, p.2657-2660, 2004.

LANA, S. R. V.; LANA, G. R. Q.; SALVADOR, E. D. L.; LANA, Â. M. Q.; CUNHA, F. S. A.; MARINHO, A. L.. Qualidade de ovos de poedeiras comerciais armazenados em diferentes temperaturas e períodos de estocagem. Revista Brasileira de Saúde e Produção Animal, v.18, n.1, p.140-151, 2017.

LEANDRO, N. S. M.; DEUS, H. A. B.; STRINGHINI, J. H.; CAFÉ, M. B.; ANDRADE, M. A.; CARVALHO, F. C.. Aspectos de qualidade interna e externa de ovos comercializados em diferentes estabelecimentos na região de Goiânia. Ciência Animal Brasileira, v.6, n.2, p.71-78, 2005.

LIMA, W. K. S.; BARROS, L. S. S.; SILVA, R. M.; DEUS, T. B.; LIMA, D. V.; SILVA, A. S.. Condições higiênico-sanitárias de ovos comercializados em feiras livres e mercados do Recôncavo da Bahia. Revista Brasileira de Higiene e Sanidade Animal, v.12, n.3, p.280-294, 2018.

PAIVA, L. L.; NASCIMENTO, K. M. R. S.; SILVA, N. S.; FREITAS, H. B.; SILVA, T. R.; OFICO, A. V.; CHAVES, N. R. B.; SILVA, L. A. R.; MACIE, V. A.; SANTOS, C. B. T.. Qualidade de ovos brancos comerciais em diferentes temperaturas de conservação e período de estocagem. Boletim De Indústria Animal, v.76, p.1-8, 2019.

PASCOAL, L. A. F.; BENTO JUNIOR, F. A.; SANTOS, W. S.; SILVA, R. S.; DOURADO, L. R. B.; BEZERRA, A. P. A.. Qualidade de ovos comercializados em diferentes estabelecimentos na cidade de Imperatriz, MA. Revista Brasileira de Saúde Produção Animal, v.9, n.1, p.150-157, 2008.

PISSINATI, A.; OBA, A.; YAMASHITA, F.; SILVA, C. A.; PINHEIRO, J. W.; ROMAN, J. M. M.. Qualidade interna de ovos submetidos a diferentes tipos de revestimento e armazenados por 35 dias a 25ㅇ․ Semina: Ciências Agrárias, v.35, n.1, p.531-540, 2014.

RIBEIRO, M. S. N. G.; SOCOLOSKI, C. M.; KOMIYAMA, M. S.; LEMOS, J. C. O.; SILVA, R. P.; RIBEIRO, M. B.; VENDRAMEL, E. C.; REGINATO, T. B.. Diagnóstico da condição de comercialização de ovos em Sinop - MT. Scientifc Electronic Archives, v.8, n.3, 2015.

SACCOMANI, A. P. O.; MORAES, J. E.; REIS, T. L.; GANECO, A. G.; THIMOTEO, M.; BORBA, H.; CALIXTO, L. F. L.;

PIZZOLANTE, C. C.. Indicadores da qualidade físico-química 
de ovos de poedeiras semipesadas criadas em diferentes sistemas de produção. Boletim de Industria Animal, v.76, p.1-15, 2019.

SANTOS NETO, J. P.; OLIVEIRA, C. C.; SILVA, P. A.; FONSECA, C. R.; CIABOTTI, E. D.. Ocorrência de aeróbios mesófilos, coliformes e Salmonella sp., em ovos comerciais higienizados por diferentes métodos. Revista Craibeiras de Agroecologia, v.4, n.1, p.7717, 2019.

SILVERSIDES, F. G.; BUDGELL, K.. The relationships among measures of egg albumen height, $\mathrm{pH}$, and whipping volume. Poultry Science, v.83, p.1619-1623, 2004.

STRINGHINI, M. L. F.; ANDRADE, M. A.; MESQUITA, A. J.; ROCHA, T. M.; REZENDE, P. M.; LEANDRO, N. S. M..

Características bacteriológicas de ovos lavados e não lavados de granjas de produção comercial. Ciência Animal Brasileira, v.10, n.4, p.1317-1327, 2009.

VANDERZANT, C.; SPLITTSTOESSER, D. F.. Compendium of methods for the microbiological examination of foods. Washington: APHA, 2010.
VIANA, B. C.; GOMES, F. A.; SILVA, R. F.; FREITAS, H. J.. Qualidade de ovos produzidos e submetidos à diferentes condições de armazenamento na Amazônia Ocidental, Acre - Brasil. Arquivos de Ciências Veterinárias e Zoologia da UNIPAR, v.20, n.4, p.201-206, 2017.

VIEIRA FILHO, L. A.; PINHO, M. D.; PINHEIRO, I. P.; SILVA, S. N.. Obtenção de óxido de cálcio a partir da casca de ovo de galinha. The Journal of Engineering and Exact Sciences, v.03, n.08, p.1159-1166, 2017.

VILELA, D. R.; CARVALHO, L. S. S.; FAGUNDES, N. S.; FERNANDES, E. D. A.. Qualidade interna e externa de ovos de poedeiras comerciais com cascas normal e vítrea. Ciência Animal Brasileira, v.17, n.4, p.509-518, 2016.

YADGARY, L.; CAHANER, A.; KEDAR, O.; UNI, Z.. Yolk sac nutrient composition and fat uptake in late-term embryos in eggs from young and old broiler breeder hens. Poultry Science, v.89, n.11, p.2441-2452, 2010.

A CBPC - Companhia Brasileira de Produção Científica (CNPJ: 11.221.422/0001-03) detém os direitos materiais desta publicação. Os direitos referem-se à publicação do trabalho em qualquer parte do mundo, incluindo os direitos às renovações, expansões e disseminações da contribuição, bem como outros direitos subsidiários. Todos os trabalhos publicados eletronicamente poderão posteriormente ser publicados em coletâneas impressas sob coordenação da Sustenere Publishing, da Companhia Brasileira de Produção Científica e seus parceiros autorizados. Os (as) autores (as) posteriormente ser publicados em coletâneas impressas sob coordenação da Sustenere Publishing, da Companhia Brasileira de Produção Cientifica e seus parce
preservam os direitos autorais, mas não têm permissão para a publicação da contribuição em outro meio, impresso ou digital, em português ou em tradução. 